\title{
Brazilian List of Threatened Plant Species: Reconciling Scientific Uncertainty and Political Decision-Making
}

\author{
Fabio Rubio Scarano ${ }^{1,2, *}$ \& Gustavo Martinelli ${ }^{3}$
}

\author{
${ }^{1}$ Conservation International, Rua Barão de Oliveira Castro 29, CEP 22460-280, Rio de Janeiro, RJ, Brasil \\ ${ }^{2}$ Laboratório de Ecologia Vegetal, Departamento de Ecologia, Centro de Ciências da Saúde, Instituto de Biologia, \\ Universidade Federal do Rio de Janeiro - UFRJ, CP 68020, CEP 21941-970, Rio de Janeiro, RJ, Brasil \\ ${ }^{3}$ Diretoria de Pesquisa Científica, Instituto de Pesquisas Jardim Botânico do Rio de Janeiro, \\ Rua Pacheco Leão 915, CEP 22460-030, Rio de Janeiro, RJ, Brasil
}

\begin{abstract}
Brazil's latest list of plant species threatened by extinction was published in September 2008. Since this was the first of its kind to be published since 1992, there was tremendous expectation and the final result was less than successful in satisfying many scientists and conservationists alike. We interpret this as a communication problem between scientists and decision-makers. We discuss the background for this problem and argue that improvements on the list will depend on agreement on the degree of scientific certainty required to define conservation status of each plant species. Moreover, we list a few ongoing actions in Brazil that indicate that this episode was essential to finally promote better communication between biodiversity scientists and decision-makers in the country.
\end{abstract}

Key words: Biodiversity Conservation, Brazil, Communication Science-Decision Making, Endangered Species List, Scientific Uncertainty.

\section{Introduction}

[...] A single thread links the most esoteric sciences and the most sordid politics, the most distant sky and some factory in the Lyon suburbs, dangers on a global scale and the impending local elections or the next board meeting. The horizons, the stakes, the time frames, the actors - none of these is commensurable, yet there they are, caught up in the same story. (Latour, 1993)

Science has reached an era when it begins to recognise its uncertainties while society urgently demands decisions on matters that require scientific background. Moreover, the well-defined boundaries of modern science practise that placed in opposite sides nature and man are gradually replaced by a hybrid format, derived from network and translation processes between these two supposed extremes (Latour 1993; 2004). Postmodernism, as some call this era (Lyotard 1979), often places scientific subjects at the centre of value disputes where stakes are high (Sardar 2002). Biodiversity-related sciences, due to their complexity and youth (Scarano 2006, 2007), often provide examples

\footnotetext{
*Send correspondence to: Fabio Rubio Scarano

Conservação Internacional do Brasil,

Rua Barão de Oliveira Castro, 29,

CEP 22460-280, Rio de Janeiro, RJ, Brasil

E-mail: f.scarano@conservacao.org
}

of conflicts that emerge when scientific uncertainties meet problem-solving demands and political decisionmaking (e.g., Srivastava \& Vellend 2005; Botkin et al. 2007; MMA/MCT 2008). One such example is the focus of this paper: the latest Brazilian list of threatened plant species (September 23 ${ }^{\text {rd }}, 2008$; at www.mmm.gov.br/estruturas/ ascom_boletins/_arq).

This list was the first of its kind to be published since 1992 and there was tremendous expectation around it. The NGO Fundação Biodiversitas was hired by the Brazilian Ministry of Environment (MMA) to coordinate a national effort to produce new lists of threatened animal and plant species. While the production of the list of animal species proceeded with no major conflicts between scientists and decision-makers, for plants the history was otherwise and the final result was less than successful in satisfying many scientists and conservationists (see, for instance, www.ecodebate.com.br/2008/09/22). In 2005 Fundação Biodiversitas, after a consultation process to some 300 academics, handed to MMA a list that proposed 1,495 threatened plant species and 2,513 species as data deficient. Three years later the threatened species list was finally published by MMA, however with very different and rather conservative figures and in a distinct format as compared to the original proposition: 1) a list of 
472 threatened species; and 2) a list of 1,079 candidate species that are data deficient. Most of those listed by scientists as data deficient were not officially recognised as such.

In this paper we do not offer a value judgement on the decision made by MMA in this respect, nor on the quality of the science (or degree of certainty) behind the original list proposed by Biodiversitas. We assume that the situation described derives exclusively from a serious communication problem between scientists and decision-makers. This communication problem is related to a large disagreement between them on the degree of scientific certainty required for the information backing up the threatened plant species label, although criteria do seem objective (IUCN 2001). A second, important assumption is that, despite all odds, the published list of threatened Brazilian plant species is the best one Brazil has ever produced, particularly due to the astonishing growth of biodiversity-related sciences in the country in recent years (Scarano 2007, 2008a, b). These premises permeate our entire argument that is organised along four axes. First, we discuss philosophical aspects behind the threatened species concept from an environmental ethics perspective. Second, we offer the scientific viewpoint exploring current certainties and uncertainties around the threatened species concept and conservation practise. Third, we discuss this issue from a political viewpoint, to reflect the political moment Brazil went through (and still is) during the production of the list. Then, we focus on the historical problems of communicating environmental-related science to decision-making. Finally, we merge the four perspectives to propose that there is a set of ongoing political and scientific actions that might help improve communication in the short term and hopefully set the stage for a new era on biodiversity science and conservation in Brazil.

\section{Endangered Species and Environmental Ethics}

Why does a list of endangered species raise so much expectation and debate? It is a strong indicator of at least two aspects that are of interest to various sectors of society: 1) it directly indicates how man's use of natural resources negatively affects biodiversity (if we correctly assume that current extinction rates are higher than if induced only by natural, non-anthropogenic causes; see Pimm 1991); and 2) it indirectly indicates the extent to which mankind has to refrain or change its culture of natural resources utilization, due to the legal protection of such species. Human attitude in face of these facts varies along a gradient that ranges from a strictly development perspective to a strictly conservationist perspective. The extreme development perspective will place mankind above all other things, and loss of species would be justifiable if to promote material progress and improvements in human life standards. The extreme conservationist perspective will place nature above all other things and defend that all species have a right to exist and that mankind is responsible for guaranteeing this right. These two extremes of the gradient, interestingly, share a similar feature that is to consider man and nature as separate entities, which is a typical modern attitude (Latour 1993). In the first case, nature is the obstacle whereas in the latter mankind is the nuisance. As one moves along this gradient, one may recognize that man and nature are not mutually exclusive options and nature conservation and societal welfare should be able to coexist and actually bear a high level of interdependence. However, as harmonic as this thought might seem, it is undoubtedly easier to say than to do (see Skakoon 2008), particularly in countries where a large proportion of the human population lives in poverty. Thus, the typical trade-off between HDI (Human Development Index) and ESI (Environmental Sustainability Index) is not at all surprising (Martins et al. 2006). This trade-off, which has Scandinavia as a notable exception, shows that the currently predominant world's development model is one where human welfare is at the expense of natural resources.

In order to reach a stage where man and nature are reconcilable, science is a fundamental tool. Global society has largely adhered to science and scientific products set standards and parameters in all sectors (Drori et al. 2003). For instance, there are various examples showing how science has backed up first the concept and then the creation of Ministries of Environment, National Parks, and conservation initiatives all over the world (Hironaka 2003), including Brazil (Scarano 2007). There is also no doubt that scientific strength and production of knowledge are paramount to national growth and sovereignty (Scarano 2008b) and, in the case of Brazil, biodiversity and natural resources are key scientific issues since they are the country's greatest assets. It follows that science should be the backbone of any threatened species list produced in Brazil and elsewhere. But how certain must be this science? Can there be an agreement between scientists and decision-makers on what is certainty?

\section{Dealing with Uncertainty:}

\section{The Scientific Stand on Threatened Species}

The main action required for scientists to improve communication with decision-makers is to enhance the certainty around their study object. The objective criteria of the World Conservation Union (IUCN 2001) set the main guidelines for the Brazilian list (both the original one proposed by academics and the one published by MMA). Plants that fit into IUCN categories of critically endangered, endangered and vulnerable are all labeled threatened species according to Brazilian law. Species that are data deficient are also an IUCN category considered by Brazilian legislation. Despite considerable controversy (Soberon \& Medellín 2007; Cuarón \& Grammont 2007), a comparative analysis among 25 categorization systems from 20 countries revealed that IUCN (2001) system is the most appropriate for setting lists of threatened species (Grammont \& Cuarón 2006). However, despite the adequacy of this system it is 
challenged by three sources of uncertainty, as proposed by Akçakaya et al. (2000): semantic uncertainty (that arises from inexact definitions; see also Shrader-Frechette \& McCoy 1993); measurement error (that arises from lack of precise information for some of the variables or incapacity to provide precise numbers in issues such as rate of decline or even population size); and natural variability (since populations vary in space and time in response to environmental variation; see also Scarano 2009). We assume that these sources of uncertainty may have influenced the political decision to remove ca. $60 \%$ of the total number of species present in the originally proposed Brazilian list. Akçakaya et al. (2000) have proposed a method of dealing with uncertainty that can be applied to IUCN criteria without altering their rules, thresholds or intent. This type of exercise could much enhance objectivity and certainty and, although well-known to science for over eight years (it had 130 citations in Google Scholar, when assessed in May $\left.16^{\text {th }}, 2010\right)$, it was done neither by academics nor by decision-makers in the case of the current Brazilian list.

As we broaden our angle of vision, uncertainty around the threatened species issue emerges in the shape of other widely debated topics such as the species concept itself (e.g., Luckow 1995; Mallet 1995; Levin 2000; Lowe et al. 2004; Rapini 2004), species expendability (e.g., Kareiva \& Levin 2003), the extent to which red lists can set conservation priorities (e.g., Possingham et al. 2002; Keller \& Bollman 2004), the relationship between species conservation and ecosystem conservation (e.g., Pavlik 2003), the adequacy of IUCN system to biodiversity-rich developing countries (e.g., Soberon \& Medellín 2007), and even the adequacy of the typical design of conservation units to integrate protection of species, ecosystems and cultural diversity (e.g., Guevara \& Laborde 2008). Further investigation into these topics, always bearing in mind that good taxonomy is the backbone of most of these subjects (Valdecasas \& Camacho 2003), will be essential to reduce uncertainty and ameliorate communication science-decision making.

\section{Dealing with Uncertainty: the Political Stand on Threatened Species in Brazil}

United Nations' precautionary principle offers a way for decision-makers to proceed when faced by scientific uncertainty. It asserts that:

[...] when there are threats of serious or irreversible damage from a given activity, and if full scientific certainty is not attained, this activity should be avoided or strictly controlled. (United Nations, 1992)

Although logic here seems impeccable, much is left to the eyes of the reader from a biodiversity perspective (see, for instance, Whiteside 2006; Carolan 2008): what is irreversible damage? What is scientific certainty? What is strict control? Who defines it? If this principle is read from a strict development viewpoint, human activities will keep moving into wild areas since seriousness or irreversibility are uncertain to an extent that they hardly matter in face of "progress". From a strict conservation viewpoint, all developmental activities moving into wild areas in Brazil and many other countries should be halted, since our knowledge on species diversity, biogeography and behavior is often uncertain. Can these countries and their people afford any of these two options? We think not.

The imbroglio surrounding the publication of the list was contemporary to a period of economic growth and high infrastructural investment in Brazil. As we mentioned earlier, Brazil follows the classic development model of Western developed countries, where growth is much to the expense of natural resources. Since Brazilian legislation strictly limits or forbids human activities in areas where threatened species occur, the national political stand is obviously conservative as regards threatened species conservation and environmental issues as a whole. Thus, decision-makers claim for higher certainty is hardly surprising. It however escapes our immediate comprehension, and it is also beyond the scope of this analysis, why the publication of the threatened plant species list has been so problematic, whereas the threatened animal list went on smoothly to present 627 species.

The assessment made by Pielke Jr. (2002) on the science-politics interface where IPCC (Intergovernmental Panel for Climate Change) currently moves is a good analogy to our biodiversity problem discussed here. He claims that IPCC assesses knowledge on climate-change related sciences but not their policy significance, leaving interpretation in this respect free to governmental agencies or corporations. In other words, a wealth of the so-called "basic science" is turned "applied" by IPCC, and derived politics are made by decision-makers based on a variety of interpretations on the same set of information and knowledge. This is then a case of politics loosely based on science. Pielke Jr.'s conclusion that, in order to avoid politicization of science, the independent scientific community must take responsibility for assessing the significance of scientific results for policy brings us to our next topic.

\section{Communicating Biodiversity Science to Decision-Making}

Communication problems between scientists and decision-makers are often related to the distinct profiles of these two professionals. In literature, they are often related to three fundamental differences between them that regard: 1) their priorities or focus, 2) the time-scale in which they operate, and 3) their language or culture (e.g., Franck 1999; Briggs 2006; MMA/MCT 2008; Scarano 2008b). Imagining a hypothetical profile gradient from stereotype scientist to stereotype decision-maker, scientist would be individualistic, focusing on his/her own curiosity, operating in the long-term and using his/her technical jargon to thrive in a culture of debate; whereas decision-maker concern would be the 
social collectivity, having to take immediate decisions and using his/her technical jargon to promote agreements. These contrasting profiles (which sometimes may be confused with the contrast discussed earlier between the extremes of a conservation-driven to a development-driven profile) do not make communication easy. For instance, while many scientists discuss the controversial species concept - which suggests that they are not always clear about what a species is in many cases (e.g., Coyne \& Orr 2004; Scarano 2009) - decision makers use species as a key basic unit for conservation. Obviously the time-scale needed to precisely define what a species is, either as a concept or as delimitation of a given taxonomic entity, shall be much larger than the time-scale available for a decision-maker to decide whether or not to, for instance, build a road on a wild area.

In the case discussed here, it is our assumption that problems are largely related to differences in what scientists and decision-makers view as scientific certainty. Another source of problem, which is perhaps more grave, is that up to this moment, red lists in Brazil are largely seen as an end and not as a means to an end. This is clearly exemplified by the fact that in 16 years only two action plans (namely, Caesalpinia echinata Lam, the Brazilian redwood, and Dimorphandra wilsonii Rizzini) were produced out of 108 plant species listed as threatened in 1992. Surely, neither decision-makers supported and invested nor scientists dedicated research time and energy to produce such plans. From the scientists' point of view, this is quite surprising if one considers the rise in scientific productivity in recent years of biodiversity-related fields such as Plant and Animal Sciences and Ecology (Scarano 2007, 2008a, b). Although Soberon and Medellín (2007) argue that red lists can be produced for different purposes, it seems reasonable to assume that red lists in Brazil should be produced to point out which species society should target on so as to formulate action plans to conserve and, whenever possible, restore their populations to viable sizes. Thus, it can be said that the goal of inserting a species in a red list is to foster ways of taking it out of it, preferably in a very near future. This will require engagement from both scientists and decision-makers, which is perhaps a first step to promote better communication between them.

\section{Concluding Remarks}

Good communication requires at least two entities engaged in the processes of "speaking" and "listening", which is intermediated by a set of codes called "language" that is shared by both parties. However, even when both parties share a same language, communication may be hindered by bias, prejudice or, more simply, miscomprehension, which are elements that block perfect listening or clarity of speaking. In our analysis, the recent episode of the Brazilian list of threatened species has problems related to language and problems related to bias. Language, in this case, is science. However, there has to be an agreement between scientists and decision-makers on which are the criteria that define threat for a plant species. IUCN sets the criteria that Brazil currently follows that indicates the existence of a common code or language, however the problem is more subtle than that, since there is clearly a disagreement between the two parties on what the required scientific certainty is to place a given plant species on any conservation status pigeon-hole. This language problem is the necessary substrate for the emergence of prejudice, since upon disagreement objectivity looses ground to pure belief and dogmatic behaviour, i.e., when this point is reached, politicians will call scientists "esoteric" and scientists will call politicians "sordid" - to use the words of Bruno Latour in the epigraph. While we fight, biodiversity is lost at unprecedented rates.

Thus, a pact has to be made and, for that purpose, language must be calibrated, i.e. criteria must be explicit and required certainty must be defined a priori. Despite all odds, the scenario is increasingly favourable for communication improvements. The explicit mention in the resolution that published the species red list to investment on research on the species listed (both threatened and data deficient) can be seen as a commitment from the decision-makers to communicate with the scientists. This is also visible in the efforts to discuss precisely the communication problems between science and policy-making in the environmental sector (e.g., MMA/MCT 2008). The investment on the expansion of graduate training in biodiversity-related fields such as Ecology (Scarano 2008a) and the emergence of professional masters courses to enhance the formal training of professionals of the environmental sector (Scarano \& Oliveira 2005) are also very encouraging in this respect. The recent creation of the National Centre for the Conservation of the Flora at the Botanical Gardens of Rio de Janeiro (a Research Institute of the Ministry of Environment), set to promote and coordinate research and actions on threatened species and in particular to help calibrate language and codes is also a good symptom. In parallel, there is an ongoing national effort to produce the first general list of Brazilian plant species since Martius - an indispensable matrix of which the red list is a subset. Finally, shortly after the publication of the Brazilian list of threatened plant species, the State University of Feira de Santana (UEFS) and Conservation International launched a book that surveyed Brazilian rare plants (Giulietti et al. 2009). They add up to 2,291 flowering plants that have an area of occurrence smaller than $10,000 \mathrm{~km}^{2}$. This list can be treated as a solid working hypothesis to test whether or not such rare plants are indeed threatened. If so, the Brazilian official list of threatened species may be significantly expanded within a short time frame.

In conclusion, our perspective is that reconciliation between science and decision-making in Brazil on the threatened plant species issue is achievable in the short term. Actually, if we consider the 2010 targets set by the Convention of Biological Diversity, this reconciliation is extremely urgent. Decision-makers must promote a pact based on a precise 
definition of the scientific certainty required for classification of plant conservation status. Both parties, despite recent conflicts, must rid themselves of mutual prejudice and move towards agreement.

\section{Acknowledgements}

This paper is a product of "Centro Nacional de Conservação da Flora", which is hosted by the Botanical Gardens of Rio de Janeiro and sponsored by the Brazilian Ministry of Environment and the World Bank. We thank dearly C. Valladares-Pádua and T. Wendt who were kind enough to critically read the paper and produce various constructive comments (even when they did not agree with our viewpoints or our premises). FRS also thanks CNPq (Brazilian Research Council) for a productivity grant and Faperj (Rio de Janeiro Research Council) for a "Cientistas do Nosso Estado" grant.

\section{References}

Akçakaya HR et al., 2000. Making consistent IUCN classifications under uncertainty. Conservation Biology, 14:1001-1013.

Botkin DB et al., 2007. Forecasting the effects of global warming on biodiversity. Bioscience, 57:227-236.

Briggs SV, 2006. Integrating policy and science in natural resources: why so difficult? Ecological Management and Restoration, 7:37-39.

Carolan MS, 2008. Book review on Kerry H. Whiteside 'Precautionary politics'. Environmental Ethics, 30:213-214.

Coyne JA \& Orr HA, 2004. Speciation. Sunderland: Sinauer Associates.

Cuarón AD \& Grammont PC, 2007. Shortcomings of threatened species categorization systems: reply to Soberón \& Medellín. Conservation Biology, 21:1368-1370.

Drori GS et al., 2003. Science in the modern world polity: institutionalization and globalization. Stanford: Stanford University Press.

Franck G, 1999. Scientific communication - a vanity fair? Science, 286:53-55.

Giulietti AM et al., 2009. Plantas raras do Brasil. Belo Horizonte: Conservação Internacional do Brasil.

Grammont PC \& Cuarón AD, 2006. An evaluation of threatened species categorization systems used on the American continent. Conservation Biology, 20:14-27.

Guevara S \& Laborde J, 2008. The landscape approach: designing new reserves for protection of biological and cultural diversity in Latin America. Environmental Ethics, 30:251-262.

Hironaka A, 2003. Science and the environment. In Drori GS et al. (eds.). Science in the modern world polity: institutionalization and globalization. Stanford: Stanford University Press. p. 249-264.

IUCN - World Conservation Union, 2001. IUCN red list categories and criteria. Version 3.1. Gland: IUCN Species Survival Comission.
Kareiva P \& Levin SA (eds.), 2003. The importance of species: perspectives on expendability and triage. Princeton: Princeton University Press.

Keller V \& Bollmann K, 2004. From red lists to species of conservation concern. Conservation Biology, 18:1636-1644.

Latour B, 1993. We have never been modern. Cambridge: Harvard University Press.

Latour B, 2004. Politics of nature: how to bring the sciences into democracy. Cambridge: Harvard University Press.

Levin DA, 2000. The origin, expansion and demise of plant species. Oxford: Oxford University Press.

Lowe A, Harris S \& Ashton P, 2004. Ecological genetics. Oxford: Blackwell.

Luckow M, 1995. Species concept: assumptions, methods, and applications. Systematic Botany, 20:589-605.

Lyotard JF, 1979. O pós-moderno. 3rd edition. Rio de Janeiro: José Olympio Editora. (translated from the original La condition postmoderne by Barbosa RC, 1988).

Mallet J, 1995. A species definition for the Modern Synthesis. Trends in Ecology and Evolution, 10:294-299.

Martins ARP, Ferraz FT \& Costa MM, 2006. Sustentabilidade ambiental como nova dimensão do Índice de Desenvolvimento Humano dos países. Revista do BNDES, 13:139-162.

Ministério do Meio Ambiente - MMA/Ministério de Ciência e Tecnologia - MCT, 2008. Relatório final: reunião de consulta nacional à comunidade científica sobre mecanismos de avaliação científica para subsidiar a tomada de decisões políticas no âmbito da Convenção sobre Diversidade Biológica e do governo federal. Brasília.

Pavlik BM, 2003. Plants that protect ecosystems: a survey from California. Biodiversity and Conservation, 12:717-729.

Pimm SL, 1991. The balance of nature? Ecological issues in the conservation of species and communities. Chicago: University of Chicago Press.

Possingham HP et al., 2002. Limits to the use of threatened species lists. Trends in Ecology and Evolution, 17:503-507.

Rapini A, 2004. Classes or individuals? The paradox of systematics revisited. Studies in History and Philosophy of Biological and Biomedical Sciences, 35:675-695

Sardar Z, 2002. Thomas Kuhn and the science wars. In Appignanesi R. (ed.). Postmodernism and big science. Cambridge: Icon Books. p. 187-233.

Scarano FR, 2006. Prioridades para conservação: a linha tênue que separa teorias e dogmas. In Rocha CFD et al. (eds.). Biologia da conservação: essências. São Carlos: Editora Rima. p. 23-39.

Scarano FR, 2007. Perspectives on biodiversity science in Brazil. Scientia Agricola, 64:439-447.

Scarano FR, 2008a. A expansão e as perspectivas da pós-graduação em Ecologia no Brasil. Revista Brasileira de Pós-Graduação, 5:89-102.

Scarano FR, 2008b. Why publish? Revista Brasileira de Botânica, 31:189-194. 
Scarano FR, 2009. Plant communities at the periphery of the Atlantic rain forest: rare-species bias and its risks for conservation. Biological Conservation, 142:1201-1208.

Scarano FR \& Oliveira PEAM, 2005. Sobre a importância da criação de mestrados profissionais na área de Ecologia e Meio Ambiente. Revista Brasileira de Pós-Graduação, 2:90-96.

Shrader-Frechette KS \& McCoy ED, 1993. Method in ecology: strategies for conservation. Cambridge: Cambridge University Press.

Skakoon E, 2008. Nature and human identity. Environmental Ethics, 30:37-49.

Soberon J \& Medellín RA, 2007. Categorization systems of threatened species. Conservation Biology, 21:1366-1367.
Srivastava DS \& Vellend M, 2005 Biodiversity-ecosystem function research: is it relevant to conservation? Annual Review of Ecology, Evolution and Systematics, 36:267-294.

Valdecasas AG \& Camacho AI, 2003. Conservation to the rescue of taxonomy. Biodiversity and Conservation, 12:1113-1117.

Whiteside KH, 2006. Precautionary politics: principal and practice in confronting environmental risk. Cambridge: MIT Press.

Received: May 2010

First Decision: May 2010

Accepted: May 2010 